\title{
Social and household factors affecting child health checkup attendance based on a household survey in Japan
}

\author{
Tsutomu SHIODA ${ }^{1,2 *}$, Masaaki MATSUURA ${ }^{\mathbf{1}}$, Yoshiharu FUKUDA ${ }^{\mathbf{1}}$, \\ Kenzo TAKAHASHI ${ }^{1}$ and Kazue YAMAOKA ${ }^{1}$ \\ ${ }^{1}$ Teikyo University Graduate School of Public Health, Japan \\ ${ }^{2}$ Department of Pediatrics, Shizuoka Saiseikai General Hospital, Japan
}

Received April 2, 2016 and accepted July 6, 2016

Published online in J-STAGE July 9, 2016

\begin{abstract}
Child health checkups are an important public service to support children's development; however, many children do not attend all the child health checkups that are required by maternal and child health law (i.e., at 1 month, 4 months, 1 and a half years, and 3 years of age). This study aimed to identify social and household factors influencing child health checkup attendance. We used data from a longitudinal household panel study in Japan. The total number of subjects was 2,612 children. We extracted numerous social variables reflecting childcare and conducted logistic regression analyses. In every health checkup, the attendance rate was significantly lower for children whose birth order was $3^{\text {rd }}$ or later. Children whose father graduated from a 4-year college or whose mother had 5 or more communicating neighbors were significantly more likely to attend the 1-and-a-half-year checkup. Children whose maternal annual income was in the middle range (1.5 to 5.0 million yen) tended not to attend checkups after 1 and a half years of age. We concluded that the later birth order was the factor of non-attendance. On the other hand, high paternal educational attainment and many communicating neighbors were identified as the factors of attendance.
\end{abstract}

Key words: Child health checkup, Socio-economic status, Social capital, Social support, Birth order

\section{Introduction}

Child health checkups are one of the public support services aiming to promote the healthy development of children. The purpose of the checkups is not only to detect diseases but also to reduce parents' anxiety about childrearing and to observe children's development ${ }^{1}$. Furthermore, they provide access to various types of practical support, such as home visiting services, child-support centers, and participation in group activities. Child health checkups are a valuable chance to support children.

*To whom correspondence should be addressed.

E-mail: tsutomu.shioda@gmail.com

(C2016 National Institute of Occupational Safety and Health
In Japan, child health checkups are officially conducted at 4 months, 1 and a half years, and 3 years of age. They are required by maternal and child health law and are performed by the municipality. The checkups involve many aspects, for instance, measurement of height, weight, and head circumference, motor and language milestones reached, detection of critical diseases, and identification of parental anxiety about child-raising. Children and parents can receive practically the same services anywhere in Japan for free. All children ought to have these official checkups, but in fact, the average percentage of attendance of child health checkups in Japan is $95.5 \%$ at 4 months, $94.8 \%$ at 1 and a half years, and $92.8 \%$ at 3 years of age ${ }^{1)}$. This means that many children fail to attend the official child health checkups. In addition to the official checkups, 
an additional checkup at 1 month of age is commonly conducted in Japan. This is not mandatory, but most parents at this time take their children to a clinic or the hospital where they are born in order to check their development.

There are many problems in relation to child health; in particular, child maltreatment is one of the most critical issues globally ${ }^{2}$. In Japan, it is an urgent task to prevent children from suffering from abuse and neglect. According to a report on child abuse in Japan, the number of children who died from abuse was 69 in 2015, but before that, it had remained at a high level (about 100 children annually) for 10 years ${ }^{3)}$. Many of the children who died from abuse did not have regular health checkups ${ }^{4)}$. In Japan, the second phase of the campaign Healthy Parents and Children 21 (in Japanese: Sukoyaka Oyako 21 dainiji) was launched in 2015 with the prevention of child abuse as one of the major items on its agenda ${ }^{5,6}$; and decreasing the rate of children failing to attend health checkups as another of its targets. Thus, it is important to tackle the issue of missed child health checkups and discuss useful measures to improve this situation.

To our knowledge, few studies have examined the factors influencing child health checkup attendance using population-based data. Few quantitative data analyses focusing on social factors have been done in the past; thus, the most important variables impacting on health checkup attendance are unknown. Some previous studies have proven that socio-economic status (SES) is associated with certain health services for children. For example, maternal employment and maternal lower educational level are risk factors for not being up to date with vaccinations ${ }^{7)}$. Mothers from economically disadvantaged households tend not to use mother and newborn care after birth ${ }^{8)}$. In the same way, it remains possible that SES may affect child health checkup attendance.

The purpose of this study was to clarify the factors influencing child health checkup attendance. We focused on SES, social network, social capital, and various types of household status as explanatory variables that could contribute to checkup attendance.

\section{Subjects and Methods}

Data

We used data from the Japanese Study on Stratification, Health, Income, and Neighborhood (J-SHINE), a household panel study which was performed from 2010 to 2013 in Japan. The aim and detailed methods of J-SHINE are described elsewhere ${ }^{9}$. A flowchart indicating the selec- tion of participants in our study is shown in Fig. 1. The wave 1 survey was conducted from July 2010 to February 2011. Adult residents, aged $25-50$ years, were selected randomly in 4 municipalities ( 2 in the Tokyo metropolitan area and 2 in a nearby prefecture). The participants answered the questionnaire using a computer-aided personal instrument (CAPI) which was an open-source platform, accessible via the internet from a personal computer. Each participant received a monetary incentive of $¥ 4,000$. The valid data size of wave 1 was 4,357 out of the 8,408 candidate sample (response rate: 51.8\%). Among them, those with a spouse or partner were surveyed from August to December 2011 (spouse/partner survey). The valid data size of the spouse/partner survey was 1,873 of 3,027 candidates (response rate: $61.9 \%$ ). Similarly, those with children aged less than 18 years were investigated from August to December 2011 (child survey). Its valid data size was 1,520 of 2,244 households (response rate: 67.7\%). Thus, the final total number of subjects was 2,612 children.

We made a new data set by merging the child survey into the basic wave 1 and the spouse/partner surveys, and conducted a cross-sectional study using those data.

\section{Measurement}

The primary outcome of this study was the attendance rate to child health checkups. We evaluated child health checkups at 1 month, 4 months, 1 and a half years, and 3 years of age. Respondents indicated which health checkups their children had attended by referring to their maternal and child health handbook.

We selected several variables from a few hundred questions in the J-SHINE survey ${ }^{9}$. The exposures included parental age, existence of a spouse or partner, receipt of public welfare assistance, previous or present maternal depression, maternal employment status after birth, use of parental leave, use of childcare services, help from grandmothers, educational attainment, income, and number of communicating neighbors. In addition to the items of child-rearing, we extracted several variables in relation to SES, social support, and social capital. Parental educational attainment and income were measured in order to assess SES. Maternal and paternal educational attainment was defined as the final school level achieved, and was stratified into 3 categories: from junior high school to high school, vocational school or 2-year college, and 4-year or graduate school. Annual paternal, maternal, and household incomes were assessed. Because the average annual household income was 5.3 million yen in 2013 in Japan ${ }^{10)}$, the categories of annual paternal and household incomes 


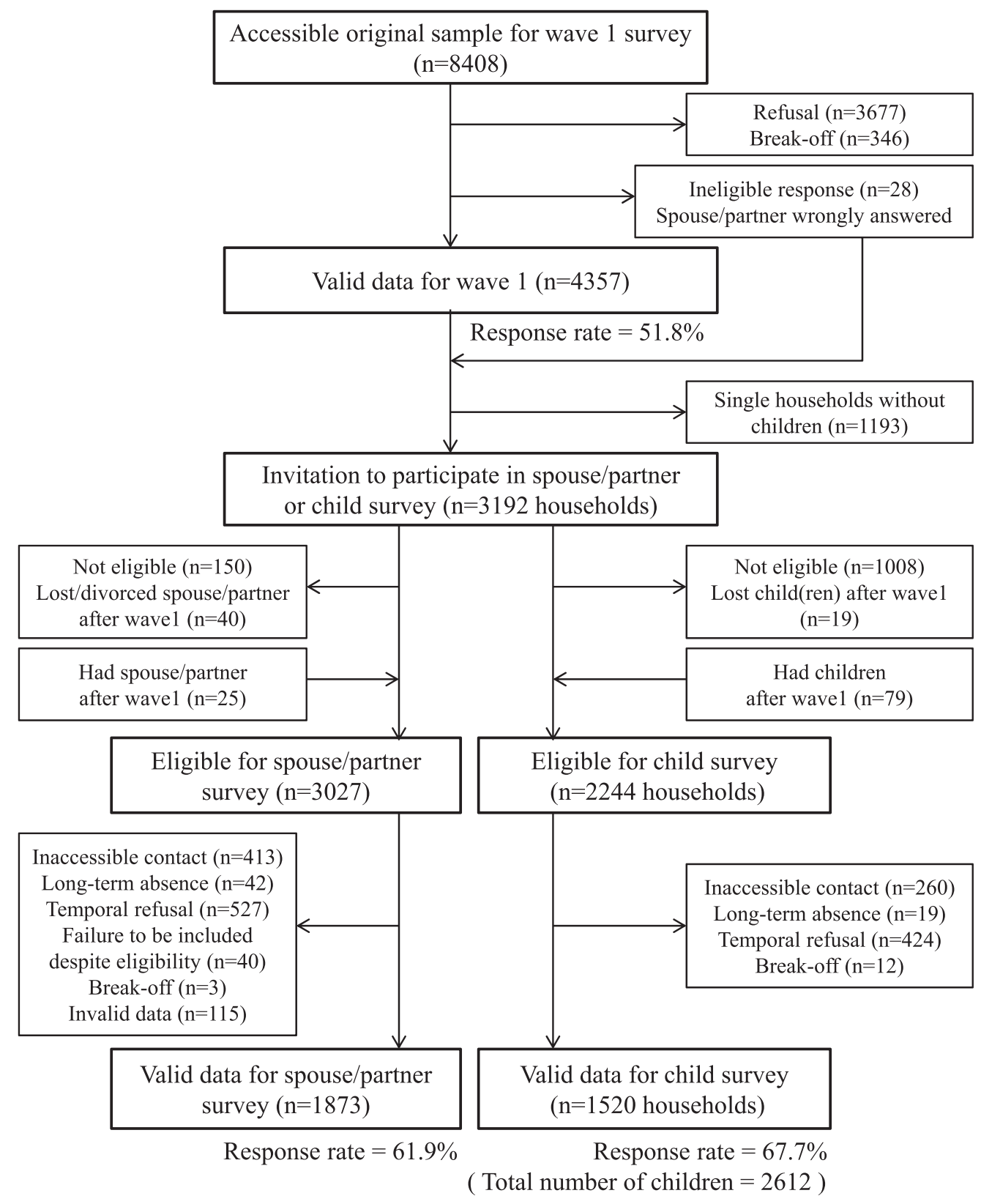

Fig. 1. Flow chart of participants recruitment in J-SHINE survey.

used were as follows: less than 4.0 million yen, 4.0 to 7.5 million yen, and more than 7.5 million yen. Given that maternal income was lower than paternal income, and that the income threshold to get tax deduction for a spouse is 1.3 million yen a year, annual maternal income was categorized into 3 low-level groups: less than 1.5 million yen, 1.5 to 5.0 million yen, and more than 5.0 million yen. In order to assess social support, access to childcare services and usage of the parental leave system were measured. Childcare services included kindergarten, day-care centers, childcare support centers, and babysitting. The number of communicating neighbors and the frequency of help from grandmothers were examined as social capital. The original classification of the number of communicating neighbors in the questionnaires involved the following categories: none, $1-4,5-19$, and more than 20; however, the number of cases in the "none" and "more than 20 " categories was small, and we therefore re-designed the categories as "fewer than 5 " and "5 or more" communicating neighbors, with the intention to obtain similar numbers in each category. The children's characteristics evaluated were sex, gestational age at birth, weight at birth, number 
of children in the household, and birth order. We excluded the unknown answers not as whole cases but only the variables with the missing data, and analyzed the significance of each exposure. We also excluded 15 extreme outliers that were clinically implausible.

\section{Data analysis}

We calculated the attendance rate for each child health checkup, and summarized the baseline characteristics of all exposures. In order to evaluate the significance of the factors influencing health checkup attendance, we applied a univariate logistic regression model. After that, we adopted a multivariate logistic regression model to calculate the odds ratio (OR) of attendance to each child health checkup for social and household factors. In the multivariate model, the statistically significant variables in the univariate model were selected and a stepwise selection method with inclusion and exclusion criteria of 0.15 was adopted. We also calculated the attendance rate for a series of health checkups. We focused on the combination of the checkups at 1 and a half and 3 years of age in particular, because they both aim to detect developmental disorders and socially support child-rearing. After we conducted a univariate logistic regression analysis for that pair of health checkups, a multivariate logistic regression model was used in the same way.

All statistical analyses were conducted using SAS (version 9.3; SAS Institute Inc., Cary, NC). We set the statistical significance level at 0.05 (two-sided).

\section{Ethical considerations}

The J-SHINE study was approved by the ethics committee of the Graduate School of Medicine of the University of Tokyo. We obtained official approval to use the data from the J-SHINE data management committee. Since the data from J-SHINE had already been converted to ID numbers, personally identifiable information was not accessible.

\section{Results}

Table 1 shows the baseline characteristics of all exposures and outcomes. The attendance rates for the child health checkups were $99.6 \%$ at 1 month, $97.5 \%$ at 4 months, $97.4 \%$ at 1 and a half years, and $96.0 \%$ at 3 years of age. The older the children, the lower the attendance rate. In general, parental educational attainment was high: $54.9 \%$ of fathers had graduated from 4 -year college or graduate school, and $72.6 \%$ of mothers had completed vocational high school or higher. Whereas $68.8 \%$ of mothers earned less than 1.5 million yen per year, $42.2 \%$ of the household incomes were over 7.5 million yen per year. Few households had received public welfare assistance. Most of the parents were married or had a partner and $2.8 \%$ were single parents. Mothers who used parental leave comprised $31.2 \%$, and $46.1 \%$ worked after birth. Those who had 5 or more communicating neighbors comprised $50.1 \%$ of mothers and $65.1 \%$ of fathers. As for the number of children and birth order, $27.0 \%$ of households had 3 or more children, and the birth order of $11.6 \%$ of children was $3^{\text {rd }}$ or later.

Only significant variables based on the univariate logistic regression model are shown in Table 2. For every health checkup, the later birth order was a significant factor of non-attendance. Additionally, other significant variables were as follows: household income in the 4-month checkup; paternal educational attainment, maternal/household income, maternal employment after birth, using childcare services, communicating neighbors with mother, and number of children in the 1-and-a-half-year checkup; and parent's age at the time of birth, maternal educational attainment, maternal income, maternal employment after birth, using childcare services, communicating neighbors with mother, gestational age at birth, and number of children in the 3-year checkup.

Table 3 summarizes the association between parents' or children's factors and child health checkup attendance in the multivariate logistic regression model with stepwise selection. Birth order was a significant variable for every health checkup. The attendance rates significantly decreased if the birth order of children was $3^{\text {rd }}$ or later (OR: 0.15, 95\% CI: $0.05-0.54,1$ month; OR: $0.19,95 \%$ CI: $0.08-0.41,4$ months; OR: $0.08,95 \%$ CI: $0.02-0.26,1$ and a half years; OR: $0.29,95 \%$ CI: $0.11-0.83,3$ years). For the 1-and-a-half-year checkup, aside from the birth order being a factor of non-attendance, children were significantly more likely to attend the health checkup if the father graduated from 4-year college or higher (OR: 7.21, 95\% CI: $2.38-31.27)$ and if the mother had 5 or more communicating neighbors (OR: 3.93, 95\% CI: 1.49-12.42).

We evaluated the results not only for each checkup but also for a combination of them. As shown in Table 1, there were 11 children who did not attend the 1-month health checkup. Among them, 3 children did not attend any of the checkups. Regarding the set of the 1-and-a-half-year and 3-year checkups, 29 children (1.2\%) did not attend either of them. Table 4 addresses the results of the 1 -anda-half-year and 3-year checkups. We analyzed the factors of non-attendance to both checkups. Like the results for 
Table 1. Attendance rate for child health checkups and characteristics of parents and children

\begin{tabular}{|c|c|c|c|c|c|}
\hline \multirow[b]{2}{*}{ Attendance rate for child health checkups } & \multicolumn{2}{|c|}{$\mathrm{N}(\%) /$ mean $(\mathrm{SD})$} & \multirow[b]{2}{*}{ Maternal age at time of birth, years-old } & \multicolumn{2}{|c|}{$\mathrm{N}(\%) /$ mean $(\mathrm{SD})$} \\
\hline & & & & 30.2 & (4.3) \\
\hline 1-month-old health checkup & & & Paternal age at time of birth, years-old & 32.3 & $(5.1)$ \\
\hline Not received & 11 & $(0.4 \%)$ & Mothers with past history of depression & & \\
\hline Received & 2,557 & $(99.6 \%)$ & None & 2,453 & $(94.6 \%)$ \\
\hline 4-month-old health checkup & & & Depression & 140 & $(5.4 \%)$ \\
\hline Not received & 65 & $(2.5 \%)$ & Childcare services & & \\
\hline Received & 2,492 & $(97.5 \%)$ & Not used & 1,330 & $(51.4 \%)$ \\
\hline 1-and-a-half-year-old health checkup & & & Used & 1,258 & $(48.6 \%)$ \\
\hline Not received & 66 & $(2.6 \%)$ & Maternal employment status after birth & & \\
\hline Received & 2,477 & $(97.4 \%)$ & Did not work & 657 & $(53.9 \%)$ \\
\hline 3-year-old health checkup & & & Worked & 561 & $(46.1 \%)$ \\
\hline Not received & 102 & $(4.0 \%)$ & Parental leave (mother) & & \\
\hline Received & 2,434 & $(96.0 \%)$ & Not used & 874 & $(68.8 \%)$ \\
\hline Parents & & & Used & 397 & $(31.2 \%)$ \\
\hline Maternal educational attainment & & & Parental leave (father) & & \\
\hline$\leq$ High school & 719 & $(27.4 \%)$ & Not used & 1,258 & $(99.0 \%)$ \\
\hline Vocational school and 2-year college & 1,229 & $(46.9 \%)$ & Used & 13 & $(1.0 \%)$ \\
\hline 4-year college and graduate school & 672 & $(25.7 \%)$ & Help from child's maternal grandmother & & \\
\hline Paternal educational attainment & & & Not frequent & 1,583 & $(64.3 \%)$ \\
\hline$\leq$ High school & 678 & $(26.6 \%)$ & Frequent & 880 & $(35.7 \%)$ \\
\hline Vocational school and 2-year college & 473 & $(18.5 \%)$ & Help from child's paternal grandmother & & \\
\hline 4-year college and graduate school & 1,402 & $(54.9 \%)$ & Not frequent & 2,030 & $(84.8 \%)$ \\
\hline Annual maternal income & & & Frequent & 363 & $(15.2 \%)$ \\
\hline$\leq 1.5$ million yen & 1,004 & $(68.8 \%)$ & Number of neighbors communicating wi & & \\
\hline $1.5-5.0$ million yen & 347 & $(23.7 \%)$ & $0-4$ & 1,291 & $(49.9 \%)$ \\
\hline$\geq 5.0$ million yen & 112 & $(7.7 \%)$ & $\geq 5$ & 1,294 & $(50.1 \%)$ \\
\hline Annual paternal income & & & Number of neighbors communicating wi & & \\
\hline$\leq 4.0$ million yen & 366 & $(17.2 \%)$ & $0-4$ & 1,482 & $(65.1 \%)$ \\
\hline $4.0-7.5$ million yen & 1,128 & $(52.9 \%)$ & $\geq 5$ & 795 & $(34.9 \%)$ \\
\hline$\geq 7.5$ million yen & 637 & $(29.9 \%)$ & Children & & \\
\hline Annual household income & & & Male & 1,348 & $(51.6 \%)$ \\
\hline$\leq 4.0$ million yen & 282 & $(13.0 \%)$ & Female & 1,263 & $(48.4 \%)$ \\
\hline $4.0-7.5$ million yen & 973 & $(44.8 \%)$ & Age at study, years-old & 8.0 & $(5.0)$ \\
\hline$\geq 7.5$ million yen & 916 & $(42.2 \%)$ & Gestational age at birth, weeks & 38.8 & $(2.0)$ \\
\hline Public welfare assistance (mother) & & & Weight at birth, $g$ & $3,011.0$ & $(441.1)$ \\
\hline Not received & 2,570 & $(99.8 \%)$ & Number of children & & \\
\hline Received & 5 & $(0.2 \%)$ & 1 & 496 & $(19.0 \%)$ \\
\hline Public welfare assistance (father) & & & 2 & 1,410 & $(54.0 \%)$ \\
\hline Not received & 2,286 & $(99.9 \%)$ & $\geq 3$ & 705 & $(27.0 \%)$ \\
\hline Received & 2 & $(0.1 \%)$ & Birth order & & \\
\hline Spouse/Partner & & & 1 st & 1,330 & $(50.9 \%)$ \\
\hline Married & 2,511 & $(97.2 \%)$ & 2nd & 977 & $(37.4 \%)$ \\
\hline Single parent & 73 & $(2.8 \%)$ & $\geq 3 \mathrm{rd}$ & 304 & $(11.6 \%)$ \\
\hline
\end{tabular}

Childcare services means kindergarten, day-care center, childcare support center and babysitting.

$\mathrm{N}$ : number with omission of missing values and unknown answers.

the checkup at 1 and a half years old, paternal educational attainment (4-year college or higher) and the later birth order were significant variables in the univariate model. Maternal and household income, gestational age at birth, and number of children were also factors that influenced checkup attendance. According to the multivariate logistic regression model, the attendance rate to both checkups was significantly lower if maternal income was 1.5 to 5.0 million yen (OR: $0.33,95 \%$ CI: $0.12-0.95)$ and the birth order of children was $3^{\text {rd }}$ or later (OR: $0.19,95 \%$ CI: $0.07-0.53$ ). 


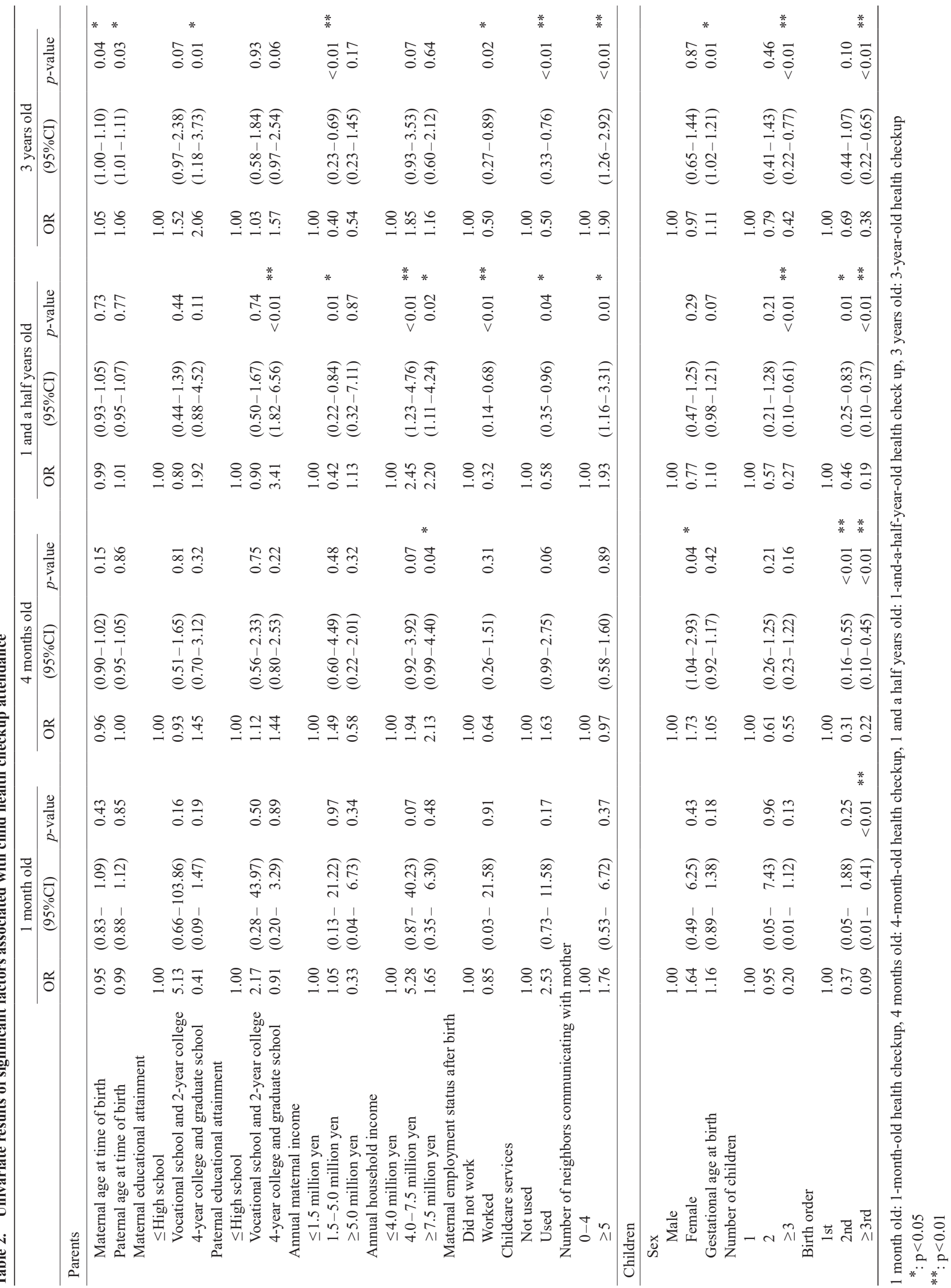


Table 3. Results of factors associated with child health checkup attendance based on multivariate logistic regression analysis

\begin{tabular}{lccc}
\hline & OR & $(95 \% \mathrm{CI})$ & $p$-value \\
\hline 1-month-old health checkup & & & \\
\hline Birth order & & & \\
$\quad$ 1st and 2nd & 1.00 & & \\
$\quad$ 3rd & 0.15 & $(0.05-0.54)$ & $<0.01$ \\
\hline 4-month-old health checkup & & & \\
\hline Birth order & & & \\
1st & 1.00 & & \\
2nd & 0.32 & $(0.16-0.62)$ & $<0.01$ \\
$\quad \geq 3$ rd & 0.19 & $(0.08-0.41)$ & $<0.01$ \\
\hline 1-and-a-half-year-old health checkup & & & \\
\hline Paternal educational attainment & & & \\
$\quad$-Vocational school and 2-year college ${ }^{\dagger}$ & 1.00 & & \\
4-year college and graduate school & 7.21 & $(2.38-31.27)$ & $<0.01$ \\
Number of neighbors communicating with mother & & & \\
0-4 & 1.00 & & \\
$\quad \geq 5$ & 3.93 & $(1.49-12.42)$ & 0.01 \\
Birth order & & & \\
1st & 1.00 & & \\
2nd & 0.20 & $(0.06-0.59)$ & $<0.01$ \\
$\quad \geq 3$ rd & 0.08 & $(0.02-0.26)$ & $<0.01$ \\
\hline 3-year-old health checkup & & & \\
\hline Gestational age at birth & 1.24 & $(1.06-1.41)$ & $<0.01$ \\
Birth order & 0.29 & $(0.11-0.83)$ & 0.01 \\
1st and 2nd & & & \\
$\quad \geq 3$ rd & & & \\
\hline
\end{tabular}

Based on stepwise selection.

${ }^{\dagger}$ Two categories are pooled through variable selection.

\section{Discussion}

This study indicates that the later birth order is the significant factor of non attendance to child health checkups, while high paternal educational attainment and the existence of many communicating neighbors are the significant factors of attendance to child health checkups. Middle maternal income could be an additional factor of nonattendance.

Children whose birth order is later tend not to receive health checkups. In particular, if the birth order of children is $3^{\text {rd }}$ or later, the attendance rates to health checkups decreases. A possible reason for this could be that parents' worries about their later children may decrease as they gain experience and learn to look after them. They might get used to rearing children and decide for themselves that they do not have any abnormalities. Another reason might be the issue of opportunity cost. When mothers take their children to a health center for health checkups, they have to leave their older children in someone's care. They thus need support to care for their other children. This is also considered to occur in relation to immunizations ${ }^{7}$. In Japan, nuclear families have been growing recently ${ }^{10)}$. Many parents bring up their children without the help of grandparents and relatives who in general can be easily asked to take care of siblings. It is relatively costly for parents to use temporary baby-sitting services. The amount of use of childcare services and having access to them may influence the rate of health checkup attendance.

Children with high paternal educational attainment tend to attend health checkups. A possible reason for this is the problem of health literacy. In a previous study, education status was found to be significantly associated with health information seeking ${ }^{11)}$. While the purpose of the 1-month and 4-month (early-half) checkups is simple, as it focuses mainly on detecting critical diseases and sharing childcare knowledge and skills, in the 1-and-a-half-year and 3-year (latter-half) checkups, the emphasis is on detecting devel- 
Table 4. Results of factors associated with attendance for 1-and-a-half-year-old and 3-year-old health checkups by univariate and multivariate logistic regression analyses

At least attending either of 1-and-a-half-year-old or 3-year-old health checkup vs neither

\begin{tabular}{|c|c|c|c|c|c|c|}
\hline & \multicolumn{6}{|c|}{ 1-and-a-half-year-old and 3-year-old health checkup } \\
\hline & \multicolumn{3}{|c|}{ univariate model } & \multicolumn{3}{|c|}{ multivariate model } \\
\hline & OR & $(95 \% \mathrm{CI})$ & $p$-value & OR & $(95 \% \mathrm{CI})$ & $p$-value \\
\hline \multicolumn{7}{|l|}{ Parents } \\
\hline \multicolumn{7}{|l|}{ Paternal educational attainment } \\
\hline$\leq$ High school & 1.00 & & & - & & \\
\hline Vocational school and 2-year college & 1.57 & $(0.62-4.50)$ & 0.37 & - & - & - \\
\hline 4-year college and graduate school & 4.65 & $(1.83-13.28)$ & $<0.01$ & - & - & - \\
\hline \multicolumn{7}{|l|}{ Annual maternal income } \\
\hline$\leq 1.5$ million yen & 1.00 & & & 1.00 & & \\
\hline $1.5-5.0$ million yen & 0.30 & $(0.10-0.84)$ & 0.02 & 0.33 & $(0.12-0.95)$ & 0.04 \\
\hline$\geq 5.0$ million yen & 0.77 & $(0.14-14.50)$ & 0.81 & 0.74 & $(0.13-14.00)$ & 0.78 \\
\hline \multicolumn{7}{|l|}{ Annual household income } \\
\hline$\leq 4.0$ million yen & 1.00 & & & - & & \\
\hline $4.0-7.5$ million yen & 4.13 & $(1.36-12.93)$ & 0.01 & - & - & - \\
\hline$\geq 7.5$ million yen & 1.65 & $(0.62-4.01)$ & 0.29 & - & - & - \\
\hline \multicolumn{7}{|l|}{ Spouse/Partner } \\
\hline Married & 1.00 & & & - & & \\
\hline Single parent & 0.16 & $(0.06-0.562)$ & $<0.01$ & - & - & - \\
\hline \multicolumn{7}{|l|}{ Children } \\
\hline Gestational age at birth & 1.16 & $(1.00-1.31)$ & 0.03 & - & - & - \\
\hline \multicolumn{7}{|l|}{ Number of children } \\
\hline 1 & 1.00 & & & - & & \\
\hline 2 & 0.32 & $(0.02-1.71)$ & 0.28 & - & - & - \\
\hline$\geq 3$ & 0.07 & $(0.00-0.35)$ & 0.01 & - & - & - \\
\hline \multicolumn{7}{|l|}{ Birth order } \\
\hline $1 \mathrm{st}$ & 1.00 & & & $1.00^{\dagger}$ & & \\
\hline 2nd & 0.26 & $(0.08-0.68)$ & $<0.01$ & $1.00^{\dagger}$ & & \\
\hline$\geq 3 \mathrm{rd}$ & 0.11 & $(0.03-0.31)$ & $<0.01$ & 0.19 & $(0.07-0.53)$ & $<0.01$ \\
\hline
\end{tabular}

Only statistically significant variables are shown, which are included in the murtivariate model.

$\dagger$ : Two categories are pooled through variable selection.

opmental disorders and supporting children's social development. Dental checkups are also provided from 1 and a half years of age. Therefore, in the latter-half checkups, parents with a higher educational level are more likely to understand the purpose of health checkups and expect significant benefits from them. Actually, in a previous study investigating the reasons for failing to attend health checkups, some mothers answered, "I don't feel the need for checkups" or "We get very little from the checkups."12). It is essential to understand the meaning of health checkups in order to attend them.

Children whose mothers have many communicating neighbors are more likely to have health checkups. In this time of low birth rates in Japan ${ }^{13)}$, parents with no experience in child rearing may have a shortage of knowledge and information. On the other hand, if mothers have many neighbors, they might sometimes provide one another with many types of information, also about children ${ }^{14)}$, and they may know about attending health checkups as well. It is therefore important to have good social contacts.

Children whose maternal annual income is 1.5 to 5.0 million yen tend not to have health checkups. Mothers whose income is less than 1.5 million yen are housewives; even if they work, their working hours are short. Those with an annual income over 5.0 million yen are full-time workers or management level employees and might be allowed to take a paid holiday for any reason, including issues related to their children. On the other hand, most mothers who earn 1.5-5.0 million yen are part-time workers. It may be difficult for part-time working mothers to take a day off to take their children to health centers. This is greatly affected by the attitude of the employer. It is reported that the rea- 
sons for failing to attend child health checkups are difficulties in arranging their schedule and the busy schedules of working mothers ${ }^{15}$. Little attention to working mothers can lead to failure to attend child health checkups ${ }^{12}$.

In order to improve child health checkup attendance, we suggest the following 3 points be considered. Firstly, we should focus on children with later birth order. It is important to encourage parents to attend health checkups, particularly for later children. A solution for this could be to provide places and services for minding siblings. Secondly, we should make efforts to enable parents to understand the purpose of regular checkups and to meet the needs of parents. Mothers with lower education may have fewer chances to learn about the content and meaning of checkups, as they are known to experience little personal support ${ }^{16)}$. Specially, we need to consider effective ways to identify less educated or isolated mothers. The needs of parents to child health checkups are diverse, so it is also necessary to deal with flexibly. In addition, social support for working mothers should be expanded. Thirdly, especially at earlier child health checkups, we should closely follow children at high risk of abuse and neglect. Although it is not clearly demonstrated in this study, a few children do not receive early-half health checkups, and each and every child should be treated carefully. They should be supported, working together with relevant organizations. We should also consider collaborating with other health services, such as neonatal home visits ${ }^{17}$.

This study has a few limitations. The first relates to risk factors for child abuse and neglect, that is, the absence of a partner, maternal depression, receiving public welfare assistance, etc. These cases were few in this study. Among the 11 cases who failed to attend the 1-month checkup in particular, at least all of those without a partner or with depression or public welfare assistance took their children to checkups. It is not possible to identify cases of abuse or neglect in this study; therefore, it may be difficult to evaluate the factors leading to maltreatment. Secondly, there is a concern about the existence of possible biases. In this study, parents tended to be highly educated living in the urban area, and could answer the questionnaires on a computer. Those failing to attend child health checkups may have also been more likely to be unwilling to answer the questionnaires. These factors might have contributed to the relatively high overall attendance rate for child health checkups in this study. The variability in children's age should also be taken into consideration. The children's ages in this study ranged between 0 and 18 years; and thus, it is suggested that the social environment during these children's childhood might have differed from that at the time of the survey. The data on income might also not accurately reflect the actual income of parents when their children were in their childhood, as only the income at the time of the survey was recorded. Originally, the J-SHINE project was not designed to evaluate only childcare services but also various aspects that influence social stratification focusing on adults, which indicates that we might not have conducted accurate surveys in regard to childcare circumstances. More child-specific surveys and studies should be conducted in the future. Thirdly, the exposures are limited in this study. We extracted the social and household variables that are considered to be relevant to neonatal care and childcare services ${ }^{7,8)}$, but they may not be enough to assess various aspects of child-rearing. For example, details on childcare services, the actual working hours, and the amount of paid days off work may possibly affect childcare. Further studies measuring other social and economic factors are needed.

\section{Conclusions}

Later birth order is the factor of non-attendance to child health checkups. Parents' educational attainment, income, and social capital can also influence checkup attendance. The next step will involve the assessment of effective ways to improve child health checkup attendance.

\section{Competing Interests}

The authors declare that they have no competing interests.

\section{Acknowledgements}

J-SHINE was supported by a Grant-in-Aid for Scientific Research on Innovative Areas (No. 2119002) from the Ministry of Education, Culture, Sports, Science and Technology, Japan.

The authors wish to thank Dr. Masayuki Kaji, Director of Shizuoka City Public Health Center, and Ms. Yasuko Aso, Teikyo University Graduate School of Public Health, for their insightful contribution to this research.

\section{References}

1) Japan Ministry of Health, Labour and Welfare. Guide to standardized infants health checkup and health instruction. March 2015. http://sukoyaka21.jp/pdf/H27manyual_ yamazaki.pdf. Accessed December 13, 2015 (in Japanese). 
2) Gilbert R, Widom CS, Browne K, Fergusson D, Webb E, Janson S (2009) Burden and consequences of child maltreatment in high-income countries. Lancet 373, 68-81.

3) Japan Ministry of Health, Labour and Welfare. Review of child deaths with abuse (11th Report). October 2015. http:// www.mhlw.go.jp/file/06-Seisakujouhou-11900000-Koyouk intoujidoukateikyoku/0000099959.pdf. Accessed May 2, 2016 (in Japanese).

4) Yamaoka Y, Tamiya N, Fujiwara T, Yamasaki Y, Matsuzawa A, Miyaishi S (2015) Child deaths with persistent neglected experiences from medico-legal documents in Japan. Pediatr Int 57, 373-80.

5) Japan Ministry of Health, Labour and Welfare. Sukoyaka Oyako 21 (dainiji). http://sukoyaka21.jp/. Accessed February 15, 2016 (in Japanese).

6) Japan Ministry of Health, Labour and Welfare. Healthy Parents and Children 21 (second Phase). http://sukoyaka21.jp/ english.html. Accessed February 15, 2016.

7) Ueda M, Kondo N, Takada M, Hashimoto H (2014) Maternal work conditions, socioeconomic and educational status, and vaccination of children: a community-based household survey in Japan. Prev Med 66, 17-21.

8) Singh A, Padmadas SS, Mishra US, Pallikadavath S, Johnson FA, Matthews Z (2012) Socio-economic inequalities in the use of postnatal care in India. PLoS One 7, e37037.

9) Takada M, Kondo N, Hashimoto H (2014) Japanese study on stratification, health, income, and neighborhood: study protocol and profiles of participants. J Epidemiol 24, 33444.

10) Summay of Comprehensive Survey of the Living Condi- tions of People on Health and Welfare 2014. http://www. mhlw.go.jp/toukei/saikin/hw/k-tyosa/k-tyosa14/dl/16.pdf. Accessed May 2, 2016 (in Japanese).

11) Ishikawa Y, Nishiuchi H, Hayashi H, Viswanath K (2012) Socioeconomic status and health communication inequalities in Japan: a nationwide cross-sectional survey. PLoS One 7, e40664.

12) Yamamoto $K$, Inoue $M$, Kasai $Y$, Sakakihara $Y$, Nakamura Y, Suzuki Y, Miyamoto F (1996) An assessment of working mothers' atttitudes toward maternal and child health care services. J Child Health 55, 475-82 (in Japanese).

13) Japan Ministry of Health, Labour and Welfare. Annual Health, Labour and Welfare Report 2015. http://www.mhlw. go.jp/english/wp/wp-hw9/dl/summary.pdf. Accessed May 6, 2016.

14) Sampson RJ (2003) Neighborhood - Level Context and Health: Lessons from Sociology. In: Neighborhoods and Health, Kawachi I and Berkman LF (Eds.), 132-146, Oxford University Press, New York.

15) Ota Y (2004) The difficulty in child-care support and the importance of support -with the view of preventing of child abuse. Human Welfare Rev 7, 97-114 (in Japanese).

16) Mangrio E, Hansen K, Lindström M, Köhler M, Rosvall M (2011) Maternal educational level, parental preventive behavior, risk behavior, social support and medical care consumption in 8-month-old children in Malmö, Sweden. BMC Public Health 11, 891.

17) Macmillan HL, Wathen CN, Barlow J, Fergusson DM, Leventhal JM, Taussig HN (2009) Interventions to prevent child maltreatment and associated impairment. Lancet 373, $250-66$. 